\title{
EL TRÁNSITO AL CRECIMIENTO ECONÓMICO MODERNO DESDE LA PERSPECTTVA DEL CONSUMO PRIVADO DE BIENES DURADEROS: GUÍA PARA UN DEBATE
}

\author{
ANDRÉS HOYO APARICIO \\ Universidad de Cantabria
}

\begin{abstract}
RESUMEN
Se aborda el estudio de la propensión al consumo de aquellos bienes duraderos que estarían en el trasfondo de la industrialización, como fue el caso del textil. Qué cantidad se consumía, cómo fue su difusión social y espacial en el largo plazo, qué determinantes y condicionantes afectaron tanto a la cantidad como a la variedad de los que se consumía, dentro de qué pautas y a través de qué mecanismos de promoción y de venta, de qué manera incentivaron o no la producción de bienes manufacturados, son cuestiones a las que se dan respuesta a partir de la información protocolizada en localidades asentadas en ámbitos geográficos diferenciados que, en su conjunto, han proporcionado una imagen caleidoscópica bastante ajustada del carácter multidimensional de los orígenes de la industrialización.
\end{abstract}

\section{ABSTRACT}

This paper studies the propensity to consume those durable goods that are in the background of the industrial revolution, such as textiles. From the information registered in towns located in various areas, the author answers questions such as how much was consumed, what determined consumption in the long run, and what factors conditioned the amount and the diversity of the goods consumed. We also inquire what were the mechanism of sale promotion, or it there were incentives for the production of manufactured goods. In the end, the paper shows that industrialization has a multidimensional origin.

JEL Classification: N33. 
El estudio de los caminos o vías de construcción de un orden democrático estable y una economía moderna constituyó desde los años sesenta un lugar de encuentro hacia el que convergió la mayor parte de la amplia producción de las ciencias sociales en España. La Historia, en sus variadas ramas de especialización, participó de este interés ocupándose por explicar las razones históricas que permitieran entender el porqué de la entonces considerada persistente dificultad española por reconducir el doble empeño modernizador, tanto político como económico, dentro de la misma senda abierta por aquellas experiencias que se estimaron como más típicas: la Revolución francesa y la Revolución industrial inglesa. En función del grado de semejanza de cada experiencia nacional con respecto al perfil definido por estos ya desde entonces calificados modelos históricos, se alcanzaron juicios de valor conclusivos de éxito o de fracaso. El caso español se presentó así como un ejemplo claro de fracaso del proceso de modernización, dentro de un tono general interpretativo manifiestamente pesimista al enfatizar el carácter excepcional e inevitable de los acontecimientos y las etapas más características de la historia de España dentro del contexto europeo. Sin embargo, ha sido éste un pesimismo que los últimos quince años de vida política y económica han contribuido de manera acelerada a su reducción. La actual armonización con los países de nuestro entorno europeo ha ido provocando un giro radical de la anterior perspectiva de análisis, que, a su vez, no puede entenderse en su totalidad si no se tiene en cuenta la profunda renovación metodológica de la historiografía española iniciada a mediados de la década de los ochenta. Una renovada perspectiva analítica más optimista que ha dado paso a un modelo interpretativo que explica el discurrir de la historia económica de España como el de un país normal que ha seguido una trayectoria no muy distinta de la observada en los países más avanzados de nuestro entorno europeo, eso sí, con ritmos diferentes pero homologables a estos últimos en cuanto a la construcción de un nuevo marco institucional, a la definición de nuevos derechos de propiedad y a la existencia de un incremento a largo plazo de la renta acompañado de parecidos cambios en la estructura sociodemográfica, productiva y distributiva ${ }^{1}$. La historia económica española es, así, la de un proceso de modernización, bien es cierto que en muchas fases lento e intermitente,

\footnotetext{
${ }^{1}$ Fusi y Palafox (1997), pp. 11-13.
} 
pero dentro de los parámetros de lo que Crafts ha denominado la norma europea ${ }^{2}$.

Esta generalizada revisión del paradigma de la vía británica al crecimiento económico moderno invitó, por tanto, a un profundo replanteamiento de la función que dentro del desarrollo económico español desempeñaron regiones eminentemente agrícolas. En este sentido, se puede decir que hay ya un acuerdo generalizado en considerar que la producción agraria, y la del trigo en particular, creció a lo largo del siglo xIx. La década de 1990 ha sido así la de la constatación de la hipótesis de un capitalismo agrario con capacidad para articular un amplio espacio y generar el suficiente ahorro susceptible de ser empleado, en cada fase expansiva, en la dotación de infraestructuras, servicios e inversión productiva ${ }^{3}$; y esto fue posible por la existencia previa de elementos dinamizadores de suficiente entidad como para flexibilizar las anquilosadas estructuras socioeconómicas del Antiguo Régimen, como así invita a pensar, por ejemplo, el mejor conocimiento que en estos momentos tenemos sobre los intercambios comerciales en la Castilla de finales del Antiguo Régimen ${ }^{4}$. Articulada esta región en una sociedad básicamente agraria, en la que predominaba la pequeña explotación campesina de base familiar y cerealista, con unos ingresos derivados de una producción de bajo rendimiento y elevada fluctuación, después de atender el autoabastecimiento y responder a los diversos requerimientos impositivos que limitaban su renta disponible, estas explotaciones fueron capaces de procurar el suficiente volumen de excedentes comercializables y de mantener un sostenido nivel de demanda como para incentivar los intercambios a larga distancia de artículos de consumo no inmediatos y variados. Tal constatación ha ayudado a romper no pocos tópicos que habían arraigado en el panorama historiográfico español desde que se atribuyó a la débil demanda interna la principal variable explicativa del secular atraso comparativo del crecimiento industrial español ${ }^{5}$.

Constituye ésta una larga y conocida polémica historiográfica en la que inciden los proyectos desarrollados por los equipos de investigación coordinados por Bartolomé Yun y Jaume Torras, desde un enfoque que insiste en resaltar la dimensión no sólo económica, sino también social, política y cultural de un componente tan importante en la explicación del cre-

${ }^{2}$ Crafts (1985), pp. 48-69.

3 Yun (1987 y 1991), García y Yun (1997), García Colmenares (1992), García Sanz (1984), Melón Jiménez (1992), Torras y Yun (1999).

4 Miguel López (1992 y 2000).

5 Nadal y Sudriá (1993). 
cimiento como es el consumo. Desde esta perspectiva —que amplía los instrumentos metodológicos de análisis al ponderar la importancia determinante que en la expansión del consumo tienen las maneras de promoción de los productos y las formas de comercialización al por menor-, se ofrece un panorama mucho más abierto y dinámico de las regiones de la España interior en su camino al crecimiento económico moderno de lo que habitualmente se ha venido explicando; un dinamismo del que participó la sociedad rural asimilando unas pautas que se perfilaban en los enclaves urbanos más próximos.

Es éste un sugerente enfoque que aboga por el multiperspectivismo; esto es, por un nuevo marco de colaboración, en el ámbito de la historia económica, entre economistas e historiadores con capacidad para integrar y vertebrar algo tan inevitable como es la circularidad de las ciencias sociales en la explicación de procesos complejos. Una invitación, por tanto, a estudiar, sin caer en el relativismo, el funcionamiento del mercado en el marco concreto de una estructura social y de unas relaciones de poder determinadas, por cuanto que es en cada una de éstas donde alcanza su auténtica dimensión. En suma, una propuesta de análisis que promueve una comprensión más completa de los mecanismos que están detrás del crecimiento económico al incorporar los efectos de cambio social e institucional que a distintos ritmos acompañan el aumento de la producción per cápita; una propuesta, asimismo, deudora de las aportaciones de alto interés que debemos a McKendrick (Revolución del consumo), De Vries (Revolución industriosa), Roche (Cultura de las apariencias) o Levi (Herencia inmaterial), y, por tanto, que cree en la necesidad metodológica de tender oportunos puentes de colaboración con la Historia social y cultural como vía, además, de superación de cierto desencanto en que parece debatirse el porvenir de la Historia económica en su relación con la Economía; pues no hay que olvidar - como no hace mucho escribiera Carlo M. Cipolla- que la Historia, en cualquiera de sus ramas y modalidades, se refiere siempre al hombre, y éste no se puede comprender, tampoco sus actividades y decisiones, si no se ponen en juego todas las dimensiones que lo constituyen.

Qué cantidad se consumía, cuál fue su difusión social y espacial en el largo plazo, qué determinantes y condicionantes afectaron tanto a la cantidad como a la variedad de lo que se consumía, dentro de qué pautas y a través de qué mecanismos de promoción y de venta, de qué manera incentivaron o no la producción de bienes manufacturados son cuestiones cuya respuesta puedo compendiar en este texto gracias a los contenidos 
de los trabajos que integran este volumen monográfico de la Revista de Historia Económica. Trabajos que, fundamentados documental y metodológicamente en el tratamiento sistemático de inventarios post mortem, cartas de pago de dote femeninas y curadurías protocolizados en localidades asentadas en ámbitos geográficos diferenciados, abordan el análisis a la propensión al consumo de aquellos bienes duraderos que estarían en el trasfondo de la industrialización, como fue el caso del textil. Trabajos que, en su conjunto y como se verá seguidamente, nos proporcionan una imagen caleidoscópica bastante ajustada del carácter multidimensional de los orígenes de la industrialización ${ }^{6}$.

\section{II}

Todos los datos aportados permiten sostener que, tanto en cifras absolutas como relativas, se produjo un aumento continuado en el stock de textiles, fundamentalmente entre 1750 y 1860 , y muy especialmente a lo largo de las cuatro primeras décadas del siglo XIX. Dicho esto, podría albergarse la duda de que este crecimiento generalizado fuera más bien resultado de un masivo consumo de prendas usadas y viejas procedentes de mercados de segunda mano de cuya existencia y buen funcionamiento se tiene sobrada constancia, siendo, en consecuencia, muy reducido el consumo de prendas nuevas. La cuestión no es baladí, por cuanto que la constatación de un aumento de productos nuevos estaría reflejando sin ningún género de dudas un incremento real en el consumo. Del análisis de los ritmos de reposición de las prendas textiles - Tasa de reposición: que mide la proporción dentro del stock de prendas clasificadas según su estado de conservación en «nuevas», «de buen uso», «usadas» y «viejas»- se desprende algunos resultados de notable interés en esta dirección. En primer lugar, las piezas «nuevas» o «de buen uso» crecieron con el paso del tiempo; en segundo lugar, a este crecimiento contribuyeron individuos que representaban todos los grupos de niveles de riqueza patrimonial inventariada; en tercer lugar, las prendas nuevas eran más abundantes en los núcleos urbanos, mientras que era en los entornos rurales en donde la ropa «vieja»

${ }^{6}$ Los autores que firman estos artículos son conscientes de los problemas metodológicos que encierra la fuente notarial para el estudio del consumo. Sobre este particular remitimos a lector interesado a los trabajos de Yun Casalilla (1999a) y de Lencina Pérez (1999). Belén Moreno ha analizado los «puntos fuertes» $\mathrm{y}$ «puntos débiles» de los inventarios post mortem catalanes. Monserrat Durán ha fundamentado su estudio en los datos que proporcionan los libros de Manifest de los comerciantes de tejidos catalanes. 
tenía una mayor presencia. Varias razones se han considerado para explicar esta última observación, que introduce ya una primera diferenciación espacial en el ritmo de consumo. Así, unas mayores disparidades del poder adquisitivo entre la población rural con relación a la menor desviación en el medio urbano -amén de factores de tipo sociológico y cultural a los que más adelante se hará puntual referencia-, explicarían en primer término esta diferenciación; igualmente los mayores costes de transacción que llevaría aparejado el contacto con una demanda rural geográficamente más dispersa parece que dificultó un mejor contacto con el mercado de prendas nuevas.

La Función de precios bedónicos que aplica Fernando Ramos en su artículo incluido en este mismo volumen contribuye a fundamentar aún más tanto la idea de un crecimiento del consumo en todos los niveles de riqueza como la existencia de una marcada diferenciación espacial en atención a su ritmo. La Hipótesis bedónica considera que los agentes económicos valoran los bienes adquiridos por la utilidad que les reportan sus características y no por los bienes en sí mismos, es decir: lo que proporciona satisfacción al individuo no es el consumo de un determinado bien, sino las propiedades de uso que alberga dicho bien. Este método ha permitido, primero, consolidar aún más la hipótesis de que el ritmo de reposición de los artículos textiles fue creciendo lenta pero de manera sostenida entre 1750 y 1840 , por cuanto que se demuestra que una parte importante del consumo de textiles se hizo a partir de piezas nuevas; y segundo, ha permitido comprobar que este ritmo de reposición así como la calidad de los productos fue más alta en aquellos lugares que tenían una mayor apertura hacia el mercado.

\section{III}

La demanda de cualquier bien puede verse alterada debido a variaciones en el poder de compra; en este sentido la evolución que conocemos de los salarios reales e incluso del coste de la vida sugerirían la hipótesis de un consumo de bienes no alimentarios bastante reducido. Pues bien, las aportaciones de Ramos, Hoyo y Maruri -incluidos en este volumeny de Dávila Corona y García Fernández ${ }^{7}$ constatan que tanto en los grupos sociales de menor patrimonio inventariado como en áreas geográficas con

\footnotetext{
${ }^{7}$ Dávila Corona y García Fernández (2001), p. 147.
} 
reducidos niveles de renta el consumo medio de textiles creció de manera apreciable.

Esto ha llevado a interrogarse por las variables que pudieron ir determinando un mayor o menor consumo de piezas y prendas; en suma, por explicar el modelo de gasto en textiles o, dicho de otra manera, por comprender los fundamentos y mecanismos de difusión social y espacial de este tipo de consumo. A Fernando Ramos debemos un mejor conocimiento de esta preocupación en virtud de un modelo econométrico que introduce como variables explicativas de las variaciones del gasto textil la «riqueza» (valor de los patrimonios inventariados), la «renta disponible» (ingresos anuales) y dos atributos como son el «grado de urbanización» y la «profesión del cabeza de familia». Se observa así: 1 . que aunque la renta disponible disminuyera (su elasticidad era muy inferior a la de la riqueza) el gasto medio en textiles no se vio alterado de manera importante, por lo que todo apunta en dirección a creer que las familias realizaban un gasto en artículos textiles en función de su riqueza esperada y no a partir de las limitaciones que sus ingresos corrientes pudieran imponerles; 2 . que el gasto medio en textiles fue mucho más elevado en aquellas economías en las que la profesión del cabeza de familia se adscribía en el sector secundario o terciario que si, por el contrario, se orientaba hacia las actividades agropecuarias; y 3. que el gasto en textiles era considerablemente más alto en las familias que vivían en zonas urbanas que en las asentadas en el medio rural. En suma, parece confirmarse, por un lado, la hipótesis de la renta permanente (Friedman), y, por otro, la existencia de una marcada jerarquización social y segmentación espacial en el consumo textil; es decir: una, digamos, «distancia al mercado» en cuanto a ritmos, pautas y estrategias que, subrayemos, respondía más a factores de naturaleza económica - diferencias en el poder adquisitivo- que únicamente a razones de mejor o peor accesibilidad geográfica, incluso en comarcas que, por su mayor endeblez productiva, fueron muy dependientes del mercado foráneo: Liébana.

Profundicemos en estas dos observaciones: jerarquización social y segmentación espacial en el comportamiento adquisitivo. Belén Moreno ha logrado distinguir en su estudio centrado en la comarca del Penedés -último tercio del siglo XVI- cuatro estrategias de consumo que muy bien pudieran constituir un modelo perfectamente trasladable a ámbitos rurales más alejados en el espacio - Valladolid, Palencia, Liébana- y en el tiempo - segunda mitad del siglo XVII- Así, los campesinos acomodados se habrían caracterizado por «consumir mucho de poco», los campesinos peor 
dotados de tierra por «consumir poco de poco», los artesanos de la villa por «consumir poco de mucho» y los miembros de la burguesía local de las letras y de los negocios por «consumir mucho de mucho». Si complementamos esta clasificación de Belén Moreno con los resultados observados de la aplicación del modelo econométrico de Fernando Ramos, cabrían pocas dudas en considerar, en un contexto claro de difusión que iría de los enclaves urbanos al medio rural, la importancia de los grupos y las «clases medias» rurales y urbanas como impulsoras de un consumo de productos de uso doméstico que estaría en la base del desarrollo industrial. En el tránsito al crecimiento económico moderno las maneras de adornar y de vestir la casa ejemplificarían el modo en que en el ámbito urbano se fueron alterando y difundiendo las pautas de consumo de sus habitantes, tal como dejaba traslucir la notable expansión del comercio al por menor, su apuesta por la especialización, la variedad y calidad de lo ofertado, así como su concentración en llamativos establecimientos ubicados en concurridas calles. Un cambio en las pautas de consumo a observar, también, en las formas de vestir el cuerpo y de cubrir la cabeza a través de unos códigos que, indicadores de movilidad e interacción social, de vida material, de valores individuales, y de representación social, seguían, al igual que en la distribución y decoración del hogar, la estela de renovados y variados gustos de los enriquecidos hombres de negocios, demandándose una amplia gama de productos de diversa índole de entre los que tenían un peso importante los consumidos por quienes, vicariamente, se afanaban por emular los gustos de estos hombres de éxito que sucumbían al impulso de la moda y las estaciones.

\section{IV}

Este señalado proceso de «universalización» de pautas de consumo modernas - adjetivo que se reflejaría en la abundancia de tejidos de algodón, en el predominio estético de la chaqueta, chaleco y pantalón en el vestuario masculino, y en una mayor gama de colores que la variada pañolería y los cuidados adornos y complementos proporcionaban al vestido femenino-, y que siguió un doble y paralelo camino de difusión por emulación vertical - de las élites a los sectores sociales inmediatamente situados por debajo de éstas-y horizontal -entre grupos sociales equiparables-, coincidió en el tiempo con un apreciable descenso de los precios relativos del textil. 
El precio representa una variable explicativa de suma importancia del comportamiento del consumidor, máxime si tenemos en cuenta que, desde el lado de la demanda, la baja elasticidad-precio que se observa cuanto más fijamos la atención en las rentas patrimoniales de menor cuantía altera de modo apreciable la alta relación inversa que cabría esperar entre precios y cantidades. Atender, por tanto, a la evolución del comportamiento tendencial de las relaciones de intercambio entre el precio tasado de los textiles y el precio de un bien de baja elasticidad como fue el del trigo contribuiría a explicar en una proporción mayor a la hasta ahora contemplada cuestiones de gran relevancia en el estudio de las pautas de consumo, como, por ejemplo, la razón de una mayor o menor cantidad en correlación con la mayor o menor variedad y calidad de tipos de fibras, tejidos y prendas a distintos niveles de patrimonios inventariados.

Pues bien, el hecho de haberse logrado construir una muestra más o menos representativa de precios de textiles homogeneizados en atención al tipo de tejido, de prenda y de color —además de cumplir el precio de las piezas seleccionadas con el criterio de contabilizar desviaciones estándar pequeñas-, ha permitido constatar que fue, precisamente, los años comprendidos en el corte cronológico 1820-1840, el período en el que el mayor impulso observado en el consumo coincidió con un importante descenso de los precios relativos.

En general, los precios textiles siguieron la misma dinámica que el resto de los precios del mercado, y en especial del precio del trigo, pero con una particularidad añadida: cuando los precios textiles subieron en la etapa anterior a 1800 lo hicieron en menor cuantía que los precios agrícolas, de igual modo que cuando los precios textiles empezaron a caer a partir de esa fecha lo hicieron a mayor velocidad que los agrarios. Una caída, tanto en términos absolutos como relativos, de los precios tasados que afectó a las piezas de lana, lienzo y algodón. Y lo que esta observación, a su vez, podría ya indicarnos: un mayor éxito en la consecución de economías de escala dentro del proceso de producción textil, así como mejoras en la comercialización y en las formas de promoción del producto textil.

Con relación a esto, los trabajos de Montserrat Durán y Lidia Torra, que prestan especial atención a las formas de alteración y difusión de las pautas de consumo y de comercialización de prendas y piezas textiles en la Barcelona de la segunda mitad del siglo XvII, introducen en el debate importantes consideraciones que, sin duda, contribuyen a reforzar la hipótesis que desde hace algunos años viene sosteniendo en varios trabajos Bartolomé Yun a propósito de la existencia de un diferenciado dinamismo 
en el proceso de reajuste que las economías locales y regionales hubieron de acometer - al igual que en el resto de Europa - tras el fin de la expansión del siglo xv, y que dio paso a un nuevo modelo de crecimiento impulsado desde las economías del arco periférico peninsular; modelo que -como argumenta Yun - «se generalizará en el siglo xvII y sobre cuyas redes urbanas y comerciales se articulará la revolución industrial» ${ }^{8}$. Así, abundantes ejemplos de mejoras en la comercialización y en las formas de promoción de los productos que Ramos y Dávila Corona y García Fernández han observado en la Castilla de la segunda mitad del siglo XvII, nos son explicados también por Durán y Torra en Barcelona - y desde Barcelona-, pero referidos a un período muy anterior: la segunda mitad del siglo XvII. Es decir, nos enseñan lo que fue una temprana apuesta por la especialización de buen número de establecimientos dedicados a la venta al por menor de géneros textiles en atención a los cambios en la composición de la oferta y, también, en atención a los variados poderes adquisitivos de los consumidores. Proceso de especialización, por tanto, y también - -subráyese- de expansión de la demanda en una época que, de manera generalizada, se ha asociando con «crisis» y «decadencia»; una expansión que fue estimulada - como apunta Torra - por la proliferación y aceptación, entre los botiguers de teles, de créditos al comercio y, entre éstos y los clientes, de créditos al consumo.

La modalidad de crédito al comercio favoreció sobremanera la fluidez en la distribución de mercancías entre los mencionados minoristas de tejidos de la capital - Barcelona - y los de otras localidades de Cataluña y, con el tiempo, del interior peninsular; observación que sin duda resulta ser una prueba bastante consistente - y sobre esto Jaume Torras ha dejado escritas sólidas páginas- de la importancia que este mercado interior tuvo para la expansión de la producción textil catalana ${ }^{9}$. La magnitud que desde la segunda mitad del siglo xvII fue adquiriendo en las comarcas del interior peninsular la llamada diáspora catalana constituye un claro indicador de la relevancia económica de esta demanda interna ${ }^{10}$. Todos los datos que hasta ahora nos son conocidos apuntan que los tejidos que llegaban de Cataluña competían con éxito en calidad y, como ha quedado constancia, también en precios. $\mathrm{Y}$ es más, parece asimismo claro que la distribución de esta producción catalana, planificada y gestionada a través de muy compactas y competitivas redes de comercialización, contribuyó - y así lo ha

\footnotetext{
${ }^{8}$ Yun (1999b), pp. 71-72.

9 Torras (1995).

${ }^{10}$ Pérez Picazo (1996), pp. 67-75.
} 
cuantificado Ramos - a acelerar el proceso de convergencia de los precios medios textiles en la ciudad y en el campo, y entre estos dos espacios; esto es: un claro síntoma de la paulatina integración del mercado regional castellano, ya apreciable cuanto más se acercaba el siglo XIX y, con mayor intensidad, a medida que éste fue avanzando.

Qué duda cabe, por tanto, que la oferta textil catalana compitió fuertemente con la producción doméstica y la manufactura local castellana; como también parece que esta última —que en mayor número resultó del desarrollo de actividades económicas auxiliares o complementarias a que obligó el creciente endeudamiento campesino que, a su vez, vendría explicado por la primacía, a medida que avanzó el siglo xvn, de la noción de privilegio expresado en forma de mayores rentas reales, diezmos, tributos señoriales o intereses de censos consignativos-, fue cada vez más orientándose a la obtención de lanas bastas y de lienzos para un segmento de la población de menor capacidad de compra. Una producción, por tanto, en bienes inferiores sustitutivos que explicaría, por ejemplo, el hecho ya constatado de que no descendiera en Castilla el consumo de textiles por familia en periodos en que sí crecieron las rentas agrarias y los precios, o también que gracias a los ingresos adicionales que por esta actividad pudieron obtener muchos productores domésticos fuera cada vez más factible un mercado con capacidad para atender una mayor propensión a consumir tejidos más variados y de mejor calidad. Es decir, la particular transición que al crecimiento económico moderno se fue perfilando en Castilla - y así parece desprenderse de las aportaciones de Ramos y de Dávila Corona y García Fernández-, más que responder exclusivamente en su origen a la hipótesis de una revolución del consumo - un impulso de la demanda de bienes manufacturados, fundamentalmente textiles, en las economías familiares, derivado sobre todo de mecanismos de imitación propios de una sociedad en donde poco a poco se iban eliminando las barreras estamentales-, a lo que más bien se asistió fue, de forma dialéctica - el consumo activa la producción para el mercado, y viceversa-, a una revolución industriosa: la intensificación del trabajo en las familias campesinas en respuesta a un mayor endeudamiento por las razones antes apuntadas permitió reforzar sus vínculos con el mercado mediante la comercialización de los objetos producidos por dichas familias con el fin de obtener ingresos adicionales que les facilitara acceder a la adquisición de manufacturas de mayor calidad que ellas mismas no podían producir. Así, en la misma dirección argumental que han apuntado, entre otros, Berg o Wrigley, la Castilla preindustrial es un ejemplo de concurrencia de una mul- 
tiplicidad de estructuras organizativas de la producción diferenciadas del moderno sistema fabril que mostraron una excelente adaptación a las diferentes condiciones del mercado.

El marco cronológico 1700-1860 acota, pues, un escenario de larga duración en el que se representa el cambio social derivado del tránsito del Antiguo al Nuevo Régimen, y que nos introduce en una dimensión del consumo que no por desconocida ha sido menos atendida por los economistas: me refiero a la dimensión social y cultural que también está detrás de la explicación de los cambios que se observan en las pautas de consumo. Efectivamente, el precio, los precios relativos, la renta, la distribución de ésta, el tamaño de las unidades familiares, han sido variables explicativas habituales en los análisis que los economistas han emprendido en el estudio de cada «función de demanda», orillando al ámbito del ceteris paribus otras, ciertamente, de más difícil cuantificación, pero no por ello menos importantes, como son los «gustos» y las «preferencias» en la elección del consumidor.

El consumo se nos presenta, así, como un fenómeno de carácter multidimensional, que atiende a razones, por supuesto, de naturaleza económica, pero, también, que responde a patrones de cambio cultural, social y político. Como ha dejado escrito Jaume Torras, «las variaciones en la intensidad de la preferencia $\multimap$ la necesidad - por determinados bienes requieren explicaciones que van más allá del marco de la decisión individual para situarse en el de la interacción social, condicionada por elecciones anteriores y por relaciones entre individuos que la teoría económica no considera». La posibilidad de cambios en el consumo se fundamenta, por tanto, también en la existencia de cambios sociales y culturales; entendiendo por tales el tránsito de una sociedad estructurada bajo el criterio «somos todos diferentes porque no somos iguales» a una sociedad que comienza a vertebrarse en la idea de «somos todos iguales porque somos diferentes». Esta lectura social del consumo permite interpretar éste no únicamente como una forma de relación entre el individuo y el objeto, sino como un modo, ciertamente, de relación, pero de un individuo con otro individuo. Así, por ejemplo, en el mercado de la tierra, Giovanni Levi ha demostrado que se puede acordar vender una propiedad en un determinado precio en función no sólo del uso y la calidad, sino, también, de lo que socialmente 
el comprador puede representar para el vendedor; pues bien, los gustos y las preferencias en el vestir — que indudablemente están detrás de la decisión de consumir más o menos cantidad, pretender más o menos variedad, buscar a más o menos calidad - responden a parecidos códigos de relación y diferenciación entre las personas, y más en una época de transición de la sociedad de súbditos a la sociedad de individuos y ciudadanos. El mayor o menor peso de la tradición, la mayor o menor preeminencia de lo local sobre lo universal, la mayor o menor subordinación del individuo a los dictados de la comunidad, la pertenencia o no - además de la pretensión por imitar - a grupos dotadores de una determinada identidad y ascendencia social, perfilan algunos de los diversos modos de relación social —o si se prefiere, de «distancias culturales»- que, en suma, transcendiendo la monocausalidad económica, modelan lo que cada individuo desea y puede consumir y lo que, finalmente, consume.

\section{BIBLIOGRAFÍA}

BERG, Maxine (1995): «Mercados, comercio y manufactura europea», en M. BERG, (ed.), Mercados y manufacturas en Europa, Barcelona, Crítica, pp. 15-42.

- (2000): «French Fancy and Cool Britannia: The Fashion Markets of Early Modern Europe», ponencia presentada en la xxxm Settimana di Studi Fiere e mercati nella integrazione delle economie europee. Secc. XIII-XVIII, Instituto Internazionale di Storia Economica F. Dantini, Prato, 8-12 maggio, pp. 3-16.

Crafts, N. F. R. (1985): British Economic Growth during Industrial Revolution, Oxford, Clarendon.

Dávila Corona, Rosa María, y García Fernández, Máximo (2001): «El consumo de productos textiles en Valladolid, 1750-1850», Investigaciones Históricas, núm. 21, pp. 133-179.

DE VRIES, J. (1993): «Between purchasing power and the world of goods: understanding the household economy in early modern Europe», en J. BREWER y R. PORTER (eds.), Consumption and the World of Goods, London-New York, Routledge, pp. 85-132.

Fusi, Juan Pablo, y Palafox, Jordi (1997): España: 1808-1996. El desafío de la Modernidad, Madrid, Espasa-Calpe.

GARCÍA, M., y YUN, B. (1997): «Pautas de consumo, estilos de vida y cambio político en las ciudades castellanas a finales del Antiguo Régimen (Sobre algunas teorías del crecimiento económico desde la perspectiva de la demanda)», en J. I. Forté PÉrez (ed.), Imágenes de la diversidad. El mundo urbano de la Corona de Castilla (siglos XVI-XVII), Santander, Universidad de CantabriaAsamblea Regional de Cantabria, pp. 245-282.

García Colmenares, P. (1992): Evolución y crisis de la industria textil castellana. Palencia, 1750-1990: de la actividad artesanal a la industria textil, Madrid, Mediterráneo. 
GARCÍA SANZ, A. (1984): "Crisis de la agricultura tradicional y revolución liberal (1800-1850)», en Historia agraria de la España Contemporánea. I, Cambio social y nuevas formas de propiedad (1800-1850), Barcelona, Crítica, pp. 7-94.

LenCINA PÉreZ, Xavier (1999): «Los inventarios post mortem en el estudio de la cultura material y el consumo. Propuesta metodológica. Barcelona, siglo XVI», en Jaume TORRAS y Bartolomé YUN (dirs.), Consumo, condiciones de vida y comercialización. Cataluña y Castilla, siglos XVII-XIX, Valladolid, Junta de Castilla y León, pp. 41-69.

Levi, G. (1990): La berencia inmaterial. Historia de un exorcista piamontés del siglo XVII, Madrid, Nerea.

MCKEndRICK, N. (1982): «The Consumer Revolution of Eighteenth-Century England», en N. McKendrick, J. Brewer y J. H. Plumb (eds.), The Birth of a Consumer Society. The Commercialization of Eighteenth-Century England, London-Bloomington, Europe Publications Limited, pp. 9-33.

Melón Jiménez, M. A. (1992): Los orígenes del capital comercial y financiero en Extremadura. Compañias de comercio, comerciantes y banqueros en Cáceres (1773-1836), Badajoz, Diputación Provincial.

Miguel López, I. (1992): El comercio hispanoamericano a través de Gijón, Santander y Pasajes (1778-1795), Valladolid, Universidad de Valladolid.

- (2000): El mundo del comercio en Castilla y León al final de Antiguo Régimen, Valladolid.

NADAl, Jordi, y Sudrí, Carles (1993): «La controversia en torno al atraso económico español en la segunda mitad del siglo XIX (1860-1913)», Revista de Historia Industrial, núm. 3.

PÉrez Picazo, M. ${ }^{a}$ T. (1996): «Los catalanes en España en el siglo XIX», en M. ${ }^{a}$ T. Pérez Picazo, A. Segura i Mas y Ll. Ferrer i Alós (eds.), Els catalans a Espanya, 1760-1914, Barcelona, Universitat de Barcelona, Generalitat de Catalunya, pp. $67-81$.

RocHE, D. (1989): La Culture des apparences. Une bistoire du vêtement (XIII-XVIII siècle), Paris, Fayard.

TORRAS, Jaume (1995): «Redes comerciales y auge textil en la España del siglo XVII», en M. BERG (ed.), Mercados y manufacturas en Europa, Barcelona, Crítica, pp. 111-132.

TORRAS, J., y YUn, B. (dirs.) (1999): Consumo, condiciones de vida y comercialización. Cataluña y Castilla, siglos XVII-XIX, Valladolid, Junta de Castilla y León.

WRIGLEY, E. A. (1992): Gentes, ciudades y riqueza. La transformación de la sociedad tradicional, Barcelona, Crítica.

Yun Casalilla, Bartolomé (1987): Sobre la transición al capitalismo en Castilla. Economia y sociedad en Tierra de Campos (1500-1830), Salamanca, Junta de Castilla y León.

- (1991): «Mercado de cereal y burguesía en Castilla, 1750-1868 (sobre el papel de la agricultura en el crecimiento económico regional)», en B. YUN CasaliLLA (coord.), Estudios sobre el capitalismo agrario, crédito e industria en Castilla (siglos $X I X-X X)$, Salamanca, Junta de Castilla y León.

- (1999a): «Inventarios post mortem, consumo y niveles de vida del campesinado del Antiguo Régimen. Problemas metodológicos a la luz de la investigación 
internacional», en Jaume TORRAS y Bartolomé Yun (dirs.), Consumo, condiciones de vida y comercialización. Cataluña y Castilla, siglos XVII-XIX, Valladolid, Junta de Castilla y León, pp. 27-40.

- (1999b): «Del centro a la periferia: la economía española bajo Carlos Ш», Studia Histórica. Historia Moderna, núm. 20, pp. 45-75. 